\title{
Конструкция и особенности изготовления детектора одиночных фотонов на базе лавинного фотодиода InP/InGaAs/InP для квантовых коммуникаций
}

\author{
В.В. Преображенский, И.Б. Чистохин, М.А. Путято, Н.А. Валишева, Е.А. Емельянов, \\ М.О. Петрушков, А.С. Плешков, И.Г. Неизвестный, И.И. Рябцев \\ Институт физики полупроводников им. А.В. Ржанова, Новосибирск, \\ 630090, Пр. Академика Лаврентьева, 13 \\ тел:+7 (383) 333-1967, эл. почта: pvv@isp.nsc.ru
}

DOI 10.34077/RCSP2021-16

Однофотонные лавинные фотодиоды (ОЛФД) на основе гетероструктуры InP/InGaAs/InP обеспечивают поглощение на длине волны 1.55 мкм и применяются в волоконно-оптических линиях связи для реализации систем однофотонной квантовой криптографии.

Для создания ОЛФД нами были проведены следующие работы: разработка конструкции и проектирование топологии ОЛФД на основе гетероструктуры InP/InGaAs/InP, технологического маршрута его изготовления методами планарной технологии, способа и условий проведения локальной диффузии цинка с целью получения заданного профиля распределения примеси р-типа и толщины области лавинного умножения, методов контроля параметров отдельных слоев гетероструктуры и ОЛФД в целом.

Многослойная гетероструктура в совокупности с локальной диффузией $\mathrm{Zn}$, металлизацией и диэлектрическими слоями состоит из следующих частей:

1. Тыльная сторона сильно легированной подложки $\mathrm{n}^{+}-\mathrm{InP}$ с контактом;

2. $\mathrm{n}^{+}-\mathrm{InP}$ буферный слой толщиной 1 мкм и с концентрацией примеси $5 \times 10^{18} \mathrm{~cm}^{-3}$;

3. поглощающий i-слой $\operatorname{In}_{0.53} \mathrm{Ga}_{0.47} \mathrm{As}$ толщиной 1-1,5 мкм с концентрацией примеси $<10^{15} \mathrm{~cm}^{-3}$;

4. слой градиентного состава $\mathrm{i}-\mathrm{In}_{\mathrm{x}} \mathrm{Ga}_{1-\mathrm{x}} \mathrm{As}_{\mathrm{y}} \mathrm{Al} \mathrm{l}_{1-\mathrm{y}}$ толщиной 20-50 нм с концентрацией примеси 1$5 \times 10^{15} \mathrm{~cm}^{-3}$

5. n-InP слой (charge) толщиной 200 нм с концентрацией примеси $1-2 \times 10^{17} \mathrm{~cm}^{-3}$ для создания перепада электрического поля;

6. i-слой InP толщиной 3,5 мкм с концентрацией примеси $<10^{15} \mathrm{~cm}^{-3}$;

7. $\mathrm{p}^{+}$легированная локально область в i-слое InP диаметром 20 мкм, создаваемая диффузией $\mathrm{Zn}$ через окно $\mathrm{SiO}_{2}$. После создания легированной $\mathrm{p}^{+}$-области толщина области лавинного умножения составит 0,3-1,0 мкм;

8. Кольцевая металлизация Ti/Pt/Au к $\mathrm{p}^{+}$-области, создающая контакт.

Гетероструктуры выращивались методом молекулярно-лучевой эпитаксии на подложке $\mathrm{n}^{+}-\mathrm{InP}$. Основными параметрами, определяющими работоспособность ОЛФД в гейгеровском режиме как детектора одиночных фотонов являются квантовая эффективность счета (требуется 15-25\%), частота темновых импульсов (требуется менее 50 кГц) и коэффициент послепульсаций менее $15 \%$.

Для достижения предельных параметров ОЛФД, работающих в счетном режиме, требуются рекордно малые темновые токи при обратных напряжениях смещения вблизи напряжения пробоя. Для этого необходима минимизация уровня фоновых примесей в слоях гетероструктуры (п.3 и п.6 выше). Были проведены исследования влияния условий выращивания этих слоев на уровень фоновых примесей и дефектов в них с помощью сочетания методов $\mathrm{C}-\mathrm{V}$ измерений ртутного зонда и МДП структуры с послойным травлением эпитаксиальных слоев. Обсуждаются результаты проведенных исследований.

Для характеризации работоспособности чипов ОЛФД в гейгеровском режиме был разработан и изготовлен временный корпус, в котором чип устанавливается на позицию измерения с применением прижимных контактов. Конструкция корпуса позволяет оперативно проводить герметизацию, охлаждение чипа до рабочей температуры $\left(-53^{\circ} \mathrm{C}\right)$ и измерение параметров чипа (квантовой эффективности счета, частоты темновых импульсов и коэффициента послепульсаций) при засветке лазерным излучением через оптоволокно.

Достигнутые в наших образцах ОЛФД величины темнового тока при температуре 217 К вблизи напряжения пробоя (менее $\left.10^{-11} \mathrm{~A}\right)$, коэффициент лавинного умножения (25-30) в линейном режиме и частота темнового счета (менее 50 кГц при перенапряжении до 3.5 В) в режиме Гейгера не уступают результатам мирового уровня.

Работа поддержана грантом Министерства науки и высшего образования № 075-15-2020-797 (13.1902.21.0024). 